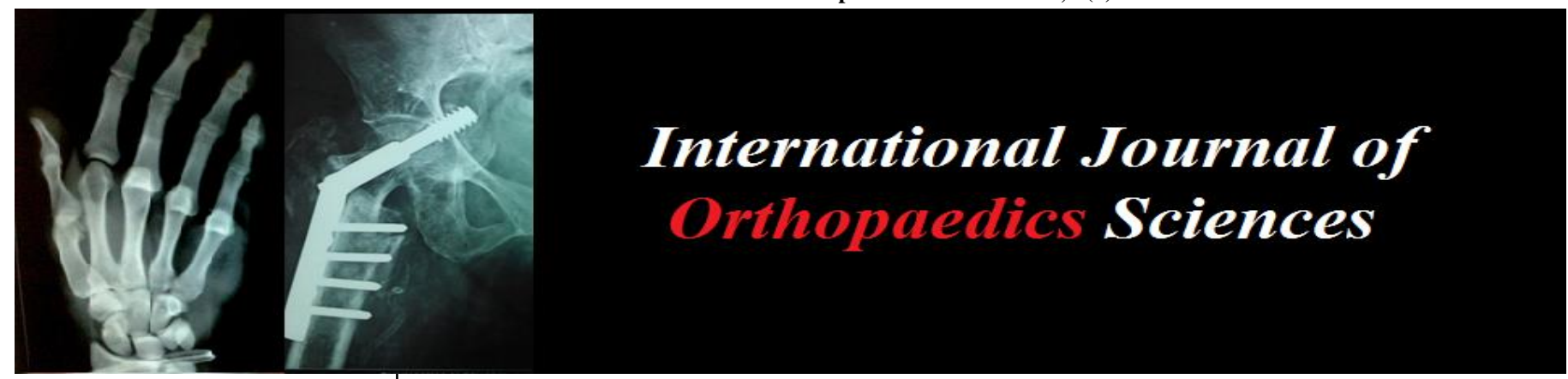

E-ISSN: 2395-1958

P-ISSN: 2706-6630

IJOS 2020; 6(3): 576-582

(C) 2020 IJOS

www.orthopaper.com

Received: 20-05-2020

Accepted: 22-06-2020

Dr. Sanjeev Dhanda

Senior Resident, Kalpana

Chawla Government Medical

College, College in Karnal,

Haryana, India

Dr. Amit Saoji

Senior Resident, Jawaharlal

Nehru Medical College, Sawangi,

Wardha, Maharashtra, India

Dr. Jaskaram Singh Virk

Senior Resident, Kalpana

Chawla Government Medical

College, College in Karnal,

Haryana, India

Dr. Vikram Singh Bath Senior Resident, Kalpana Chawla Government Medical College, College in Karnal,

Haryana, India
Corresponding Author: Dr. Sanjeev Dhanda Senior Resident, Kalpana Chawla Government Medical College, College in Karnal,

Haryana, India

\section{Functional analysis of extra-articular and intra- articular distal radius fractures managed with open reduction and internal fixation using volar locking plate} Dr. Sanjeev Dhanda, Dr. Amit Saoji, Dr. Jaskaram Singh Virk and Dr.
Vikram Singh Bath

DOI: https://doi.org/10.22271/ortho.2020.v6.i3i.2256

\section{Abstract}

Fractures of distal radius are most common fractures of the upper extremity, comes in practice and compromise $17 \%$ of all fractures and $75 \%$ of all radius-ulna fractures. Restoration of radial length, radial tilt angle and conformity of joint surface is essential for good outcomes. Improper anatomic reduction can lead to degenerative arthritis, distal radio-ulnar and metacarpal instability and ulnar impaction syndrome with resultant pain, decreased mobility, strength and function.

Various surgical modalities have been discovered as a result of these disadvantages due to conservative treatment. These include per cutaneous pinning of distal fragment, immobilisation with pins incorporated in plaster, external fixator, or if with or without bone graft and huge or if.

Keywords: Extra and intra-articulars distal end radius fracture fixation using open reduction and internal fixation with volar locking plates

\section{Introduction}

Volar locking compression plate (LCP) is a new era plate and screw system for fixing fractures $[10,11]$ The LCP has dynamic compression holes providing options for axial compression in addition to locking mechanism. The LCP can be used as a compression plate, a locked internal fixator, or a combination of both, depending on the situation.

Locking plate decreases the screw-plate toggling which prevent loss of reduction and motion at bone-screw interface and provides more rigid fixation. Rigid fixation is felt to be one key to the successful treatment of these fractures.

Fixation in osteoporotic and comminuted fractures is cumbersome to obtain proper reduction and good purchase. So with the evolution of locking compression plating for osteoporotic and peri-articular fractures especially for the comminuted fractures restoring the anatomical congruity and providing stable fixation with resulting increased stability allow for early restoration of limb function.

Volar plates allow multiple fixation points in distal fragments with locking screws recessed into screw holes to create a lower profile distally. Angulations of these distal screws create a scaffold to optimize sub chondral bone support with one or two screws devoted to fixation of lunate facet and radial styloid. Most plating systems feature oblong hole for metaphyseal fixation and plate positioning.

Advantages of volar plating are, it can be used in dorsally displaced fracture because volar cortex is usually disrupted by simple transverse line so reduction is easy, anatomic reduction of volar cortex allow restoration of radial length, radial inclination and volar tilt, it preserves vascular supply to dorsal fragment, and complication associated with dorsal plating like extensor tendon rupture and hardware irritation which are not related with volar plating because volar plate is separated from flexor tendons by pronator quadratus muscle.

Volar lock plate system are an adequate fixation method for unstable extra articular distal end radius fractures allow early mobilization because of angle stability of locking compression 
plates hold the reduction in place till the complete union taking place.

The aim of this study was to analyze the functional assesment of surgical management of distal radial fractures in adults using Orif with volar locking plate.

\section{Objectives}

1. To evaluate the role of open reduction and volar locking plate fixation followed by early mobilization of wrist joint in the treatment of fracture distal end radius.

2. To evaluate the functional, radiological outcomes and complications of locking plate system.

\section{Methodology}

Study site-kcgmc, Karnal

Type of study-Prospective, observational study

Sample-patients who were operated for distal end radius fracture with open reduction and internal fixation by volar locking plate during March 2017 to march 2018.

Duration of study-March 2017 to March 2018

Sample size-38 patients.

\section{Inclusion criteria}

1) Patient age above 18 years

2) Presenting with distal end radius fracture either intra or extra articular within $5 \mathrm{~cm}$ of wrist joint.

3) Patients present with both volar tilt and dorsal tilt of distal end radius fractures.

4) Patient giving consent for surgery

\section{Exclusion criteria}

1) Age less than 18 years

2) Having open fracture of distal end radius

3) Pathological fractures

4) Having pre-existing skin lesions.

\section{Implants used}

The volar distal radius LCP combines advantages. as it is utilizing holes for both locking and non-locking screws.

The LCP plates provide resistance against angular collapse. Instrument set has standardized drill bits, screws drivers and drill guides helps make the locking system efficient and easy to use.

\section{Plate}

The LCP distal radius plate is a $3.5 \mathrm{~mm}$ low profile stainless steel plate with a $26^{\circ}$ distal volar tilt that reduce the fracture anatomical and maintain radial inclination

The distal articular end of the plate consists of multiples (3-5) locking holes for $3.5 \mathrm{~mm}$ locking screws angled at $15^{\circ}$.

- The shaft of the plate consists of combi-holes for insertion of $3.5 \mathrm{~mm}$ locking or cortical screws.

- The plates are available in $3,4,5,6,7,8$ hole shaft length. (figure 12)

\section{Screws}

- The screws are $3.5 \mathrm{~mm}$ stainless steel self-tapping and locking screws. Threaded conical head locks securely into the threaded holes in the plate to provide angular stability.

- Locked screws allow unicortical screw fixation and load transfer to near cortex. (figure 14)

- $\quad$ Available in $6 \mathrm{~mm}$ to $30 \mathrm{~mm}$ lengths ( $2 \mathrm{~mm}$ increments)

\section{Drill bit}

- A $2.8 \mathrm{~mm}$ regular drill bit is used for all the screws.

\section{Threaded LCP drill guide}

- $\quad$ The $3.5 \mathrm{~mm}$ threaded LCP drill guide centers the $2.8 \mathrm{~mm}$ drill bit to ensure the engagement of the locking screw in the threaded hole in the plate.

\section{Surgical technique \\ Positioning}

Patient is in supine position; arm is abducted to 90degrees, supinated and placed on side table. A tourniquet enforced in arm toward axilla. $\mathrm{C}$ arm is positioned diagonally from the opposite side of the arm table. Prepping and drapping of operated site.

\section{Volar approach (modified henrys approach)}

A elongated long incision is made. The plane between the Flexor carpi radialis and the Palmaris longus was developed. The Flexor pollicis longus tendon was retracted medially and the median nerve and the other tendons were retracted towards ulna.

Pronator quadrates flap elevated to expose fracture.

Closure: After the completion of the fixation, thorough wash of the wound was given with normal saline. Wound closed in layers. Sterile dressing was applied.

\section{Post-operative protocol}

1) NBM for 4 to $6 \mathrm{hrs}$.

2) Below elbow slab application for 10 -14 days, check for pulses and circulation

3) Give antibiotic Cefuroxime $750 \mathrm{mg}$ TDS Amikacin 500 OD and Diclofenac with antacid. i.v for pain.

4) Maintain vital charting, look for any active bleeding, look for any sign of compartment syndrome.

5) Post op $x$ ray AP and lateral view.

6) Check for finger movement

7) Continue antibiotic for 3 to 5 days, continue antiinflammatory for a week.

Ask the patient to come for follow up after 10 to 12 days for suture removal

Patients followed for follow up visit on post procedure at 6 week, 3months, 6 months with distal end radius AP and lateral $\mathrm{X}$ ray and outcome recorded using o Demerit point system of Gartland and Werley.

\section{Classification}

Classifications of fracture of distal radius: Beginning with the classic description of an extra articular distal radius fracture by Abraham Colles in 1814, many authors have described about the distal radius.

This fracture takes place an inch and a half above the carpal extremity of the radius The carpus and the base of the metacarpus appear to be thrown backward so much as on first view to write a suspicion that the carpus is dislocated. There are many classifications proposed for colles fracture but more accepted and recent one is following:

\section{1) Gartland and Werley classification}

Type IA: Extra articular undisplaced

IB: Extraarticular displaced

Type II: Intraarticular undisplaced

Type III: Intraarticular displaced 
Table 1: Frykman classification of distal radius fractures

\begin{tabular}{|c|c|c|}
\hline Distal ulna fracture & No & Yes \\
\hline Extraarticular & I & II \\
\hline Intraarticular into RC joint & III & IV \\
\hline Intra Articular into RU joint & V & V1 \\
\hline Intra Articular into RC +RU Joints & VII & VIII \\
\hline
\end{tabular}

3) AO Classification ${ }^{[35]}$ : Was used in this study.

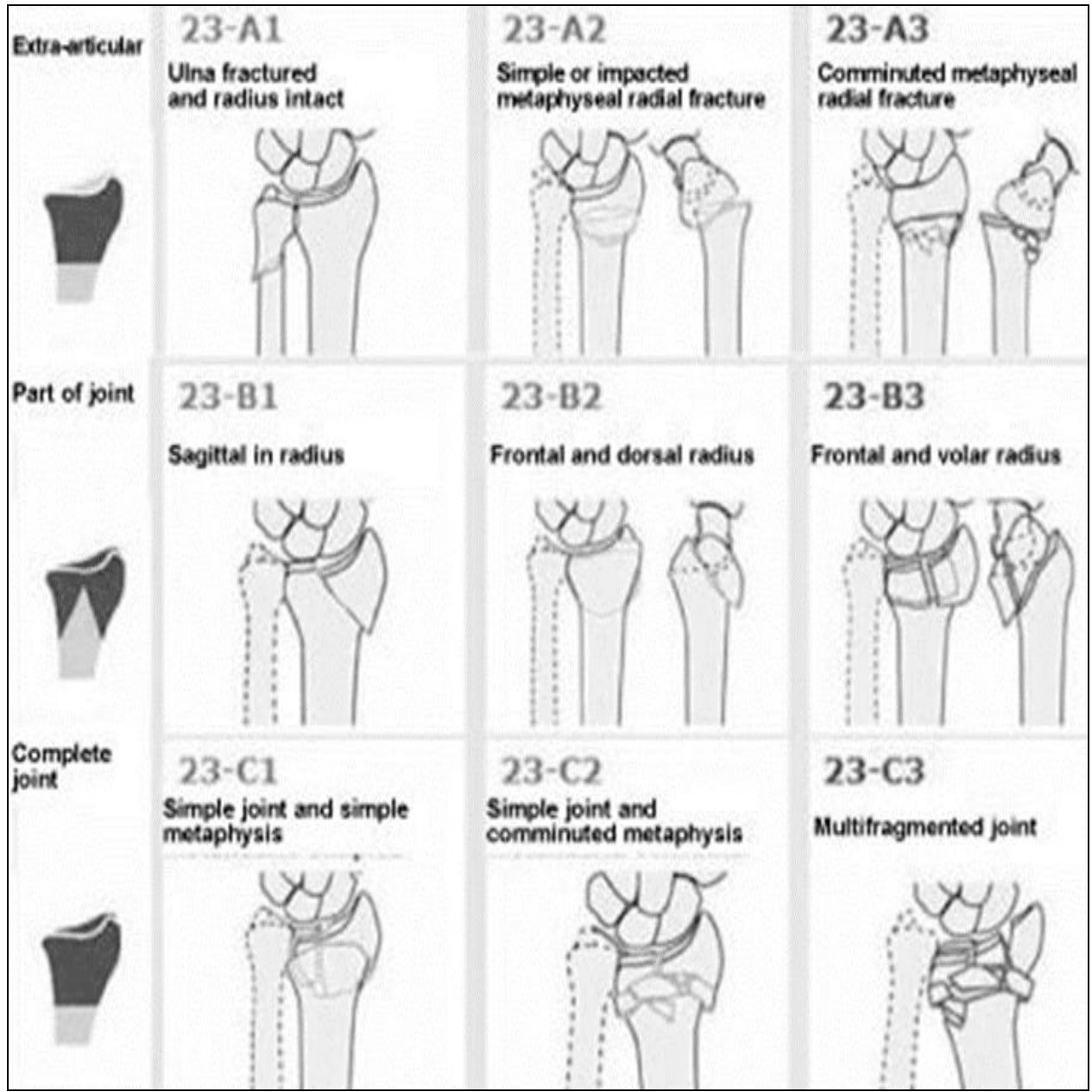

\section{Functional outcome assessment}

Table 2: Clinical assessment based on Demerit point system of Gartland and Werley

\begin{tabular}{|c|c|}
\hline Residual Deformity & Points \\
\hline Prominent ulnar styloid & 1 \\
\hline Residual dorsal tilt & 2 \\
\hline Residual elevation of hand & $2-3$ \\
\hline Point range & $0-6$ \\
\hline Subjective evaluation & 0 \\
\hline Excellent: no pain, disability, or limitation of motion & 2 \\
\hline Good: Occasional pain, limitation of Motion: no disability & 4 \\
\hline Fair: occasional pain, limitation of motion, Feeling of weakness, activities slightly restricted & 6 \\
\hline Poor: pain, limitation of motion, disability, activities more or less restricted & \\
\hline Objective evaluation* & 5 \\
\hline Loss of dorsiflexion & 2 \\
\hline Loss of ulnar deviation & 2 \\
\hline Loss of supination & 1 \\
\hline Loss of pronation & 1 \\
\hline Loss of palmar flexion & 1 \\
\hline Loss of radial deviation & 1 \\
\hline Loss of circumduction & 1 \\
\hline Pain in distal radio-ulnar joint & \\
\hline Grip strength-60\% or less of opposite side & \\
\hline
\end{tabular}




\begin{tabular}{|c|c|}
\hline Complications & \\
\hline Arthritic change & 1 \\
\hline Minimum & 2 \\
\hline Minimum with pain & 3 \\
\hline Moderate & 4 \\
\hline Moderate with pain & 4 \\
\hline Severe & 5 \\
\hline Sever with pain & $1-3$ \\
\hline Nerve complications & $1-3$ \\
\hline Loss of finger motion & $0-10$ \\
\hline Point range & \\
\hline End result point range & $0-2$ \\
\hline Excellent & $3-8$ \\
\hline Good & $9-20$ \\
\hline Fair & $21 \&$ above \\
\hline Poor & \\
\hline
\end{tabular}

Objective evaluation is based on range of motion. The minimum required for normal function: dorsiflexion 45 degrees, palmar flexion 30 degrees, radial deviation 15 degrees, ulnar deviation 15 degrees, pronation 50 degrees, supination 50 degrees.

\section{Observations and Results}

Table 1: Age distribution of cases studied $(n=38)$.

\begin{tabular}{|c|c|c|}
\hline Age Group (years) & No. of cases & \% of cases \\
\hline $20-39$ & 14 & 36.8 \\
\hline $40-59$ & 16 & 42.1 \\
\hline $60-79$ & 8 & 21.1 \\
\hline Total & 38 & 100.0 \\
\hline
\end{tabular}

Table 2: Distribution of AO classification $(n=38)$.

\begin{tabular}{|c|c|c|}
\hline AO Classification & No. of cases & \% of cases \\
\hline A2 & 7 & 18.4 \\
\hline A3 & 7 & 18.4 \\
\hline B 1 & 4 & 10.5 \\
\hline B2 & 6 & 15.8 \\
\hline B 31 & 4 & 10.5 \\
\hline C2 & 2 & 5.3 \\
\hline C3 & 2 & 5.3 \\
\hline Total & 6 & 15.8 \\
\hline
\end{tabular}

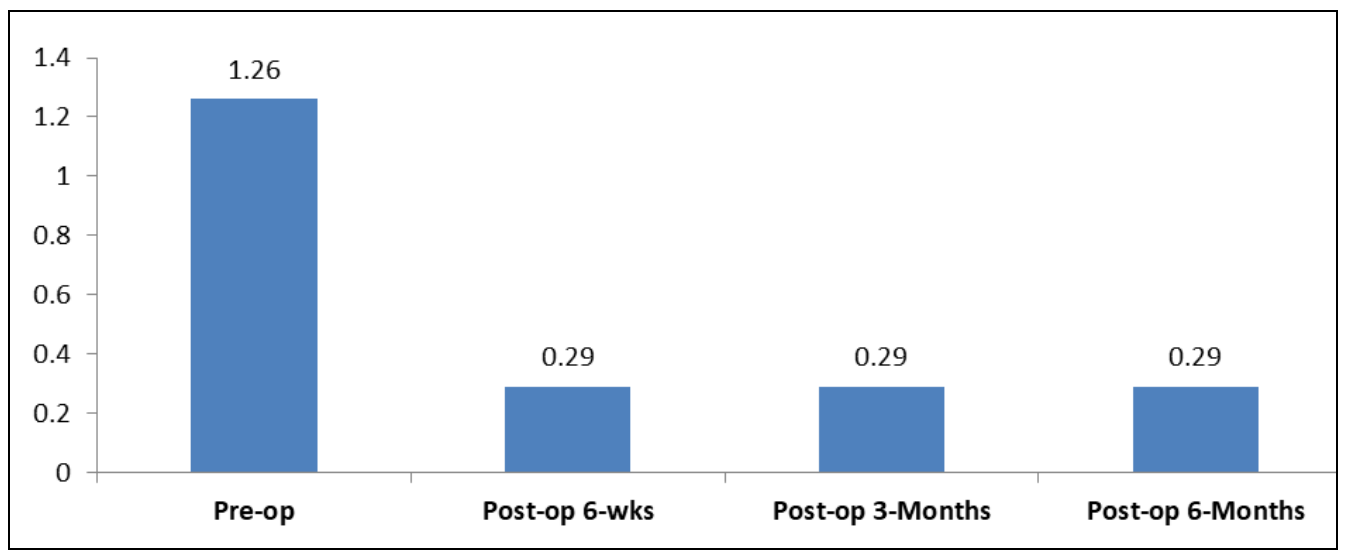

Fig 1: Comparison of pre-op and post-op mean radiological parameters (Articular Step) $(n=38)$. Height) $(n=38)$.

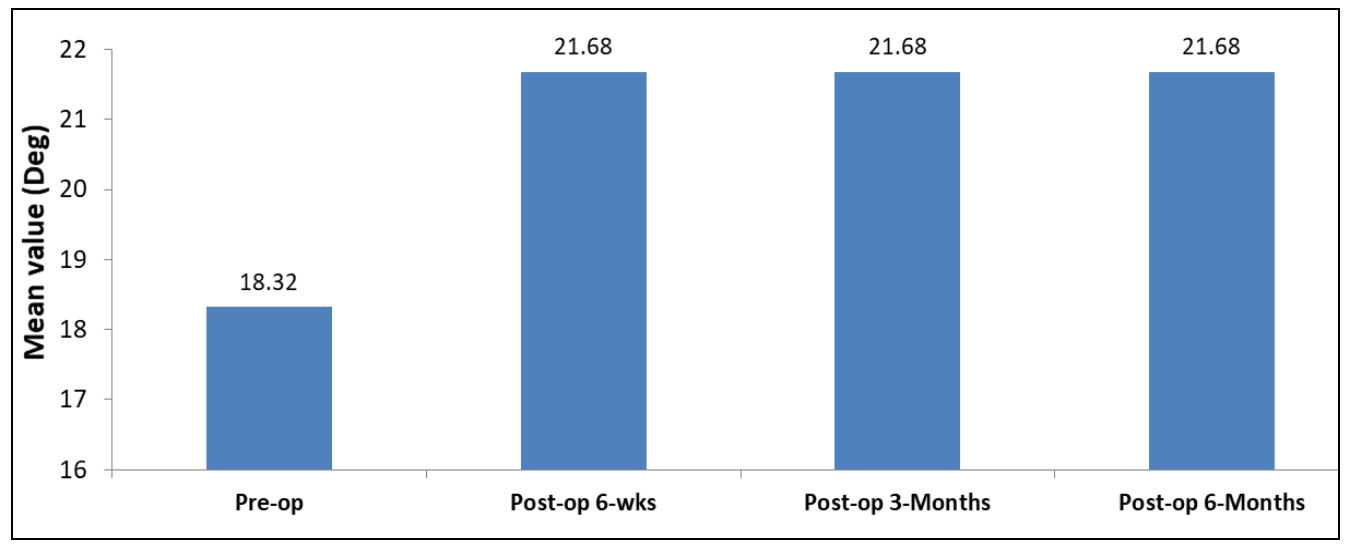

Fig 2: Comparison of pre-op and post-op mean radiological parameters (Radial Angulation) $(\mathrm{n}=38)$. 


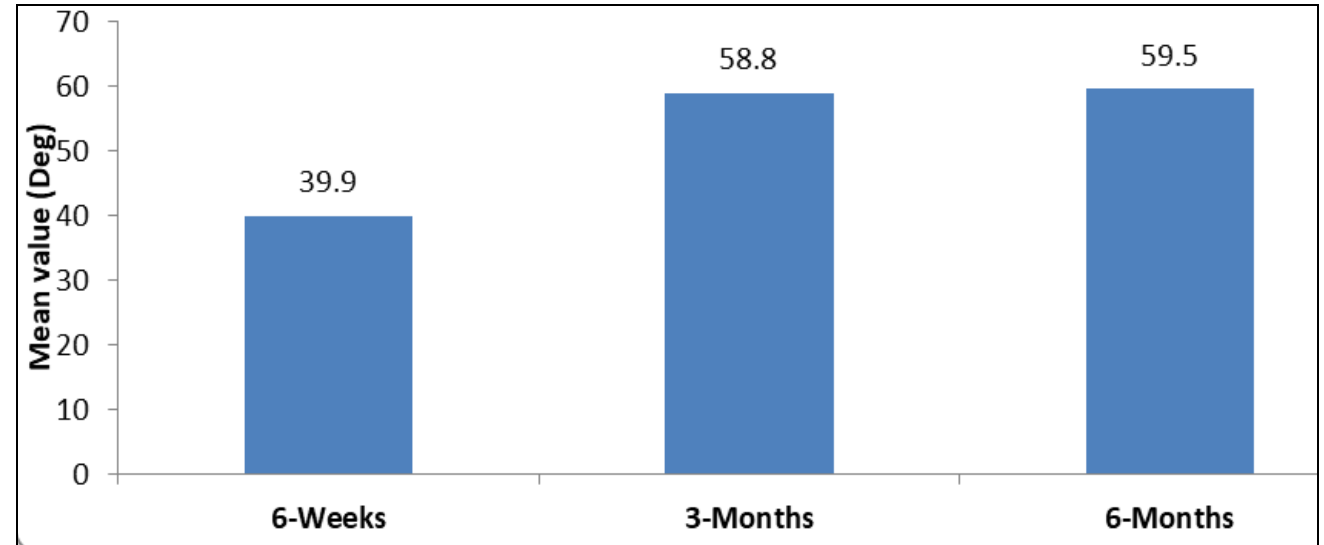

Fig 3: Comparison of post-op mean Palmer flexion $(n=38)$.

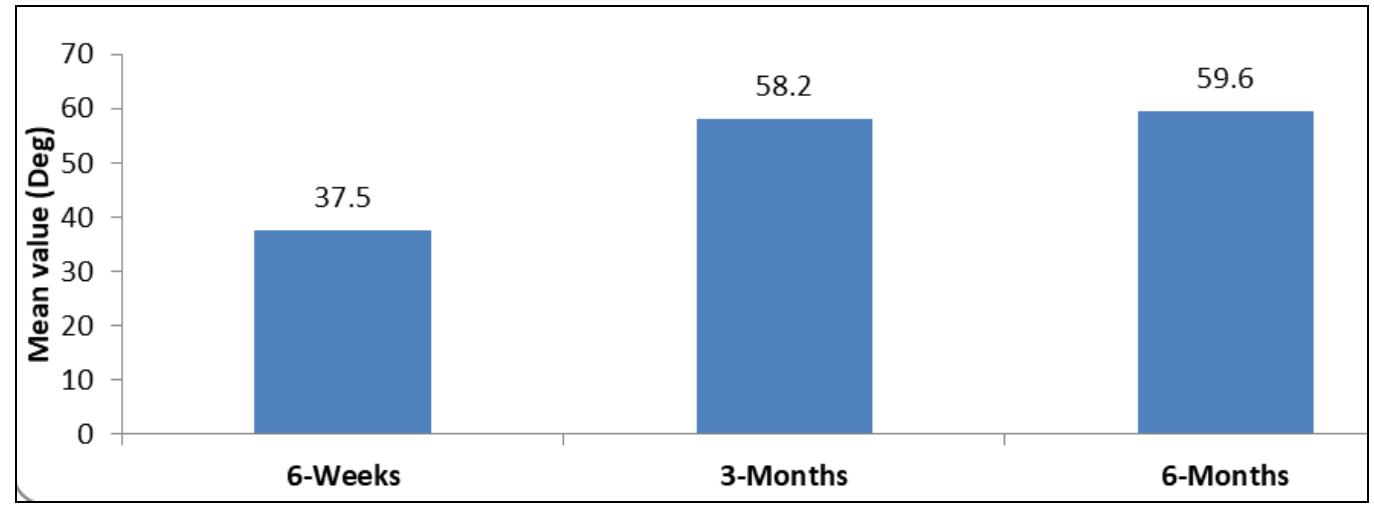

Fig 4: Comparison of post-op mean Dorsiflexion $(\mathrm{n}=38)$.

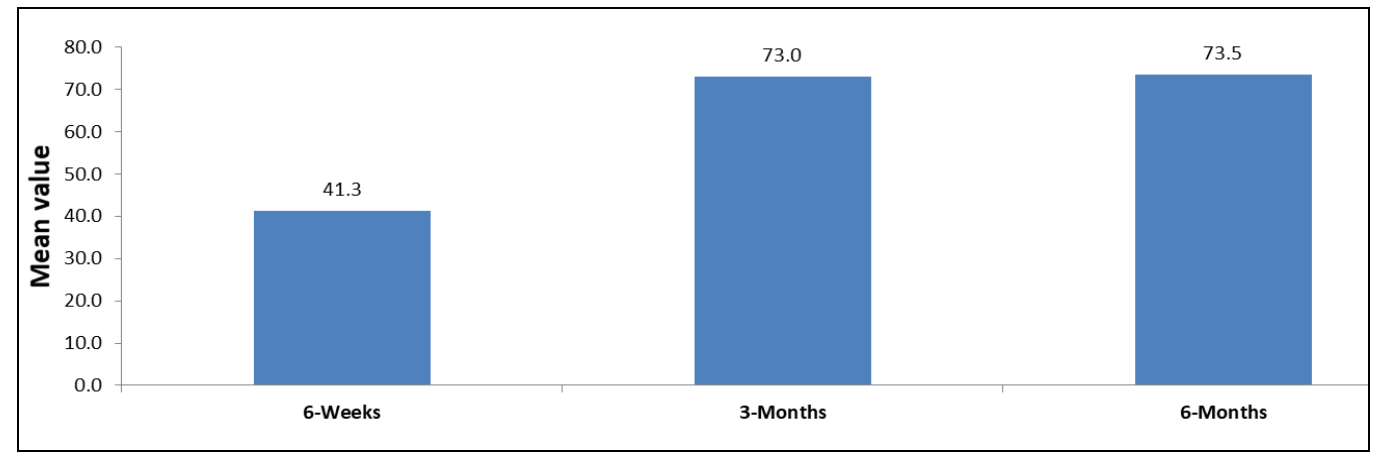

Fig 5: Comparison of post-op mean Supination $(n=38)$.

Table 3: Distribution of post-op incidence of deformity $(n=38)$.

\begin{tabular}{|c|c|c|}
\hline Deformity & No. of cases & \% of cases \\
\hline Nil & 35 & 92.1 \\
\hline Dorsal Tilt & 2 & 5.3 \\
\hline Styloid prominence & 1 & 2.6 \\
\hline Total & 38 & 100.0 \\
\hline
\end{tabular}

Of 38 cases studied, $35(92.1 \%)$ did not have any deformity post-operatively, $2(5.3 \%)$ had dorsal tilt and $1(2.6 \%)$ had styloid prominence.

Table 4: Distribution of final outcome based on functional parameters (Demerit Score) $(\mathrm{n}=38)$.

\begin{tabular}{|c|c|c|}
\hline Final outcome & No. of cases & \% of cases \\
\hline Fair & 3 & 7.9 \\
\hline Good & 10 & 26.3 \\
\hline Excellent & 25 & 65.8 \\
\hline Total & 38 & 100.0 \\
\hline
\end{tabular}

Of 38 cases studied, $3(7.9 \%)$ had fair outcome, $10(26.3 \%)$ had good outcome and 25 (65.8\%) had excellent outcome.

\section{Discussion}

a) Age distribution

Table 5: Age distribution

\begin{tabular}{|c|c|c|c|}
\hline Age & $\begin{array}{c}\text { Max age } \\
\text { (years) }\end{array}$ & $\begin{array}{c}\text { Minimum age } \\
\text { (years) }\end{array}$ & $\begin{array}{c}\text { Mean age } \\
\text { (years) }\end{array}$ \\
\hline In our study & 73 & 24 & 47.6 \\
\hline Rohit A et al. & 57 & 17 & 57 \\
\hline Killac A et al. & 77.13 & 45 & 45 \\
\hline Anakwe RE et al. & 67.8 & 48 & 48 \\
\hline
\end{tabular}

The average age of the patients in our study was 47.6 years. The eldest patient in the study was 73 years of the age and the youngest patient was 24 years old.16 of the total 38 cases in our study were between the age groups 40-59 years, as this is the active group considering the inclusion criteria and is attributed to the fact that a large number of them are engaged in outdoor activities and this fracture correlates with osteopenia. 


\section{Observations in previous studies}

- In Arora R et al. (2007) ${ }^{[7]}$ study average age of the patients was 57 years with minimum age 17 years and maximum years $79.12^{[7]}$

- In Killic A et al. (2009) ${ }^{[10]}$ study average age of the patients was 45 years with minimum age 18 years and maximum years 77.13 , which similar to our study ${ }^{[10]}$.

- In Anakwe RE et al. (2010) study average age of the patients was 48 years which is similar to our study with minimum age 22 years and maximum years $67.8^{[11]}$.

\section{b) Classification}

\section{Based on AO classification,}

In 38 patient we reported 7 case of A2 type fractures, 7 cases of A3 type fractures, 4 cases of B1 type fractures, 6 cases of B2 type fractures, 4 cases of B3 type of fractures, 2 cases of $\mathrm{C} 1$ type fracture, 2 cases of $\mathrm{C} 2$ type fracture, 6 cases of $\mathrm{C} 3$ type fractures

\section{Observations in previous studies}

- In Arora Rohit et al. (2007) ${ }^{[7]}$ study reported that 39 cases by A2, 16 cases by A3, 24 cases by $\mathrm{C} 1,30$ cases and by $\mathrm{C} 2,5$ cases by $\mathrm{C} 3{ }^{[7]}$.

- In Ayhn Kilic et al. (2009) ${ }^{[10]}$ reported that 3 cases by B2, 2 cases by B3, 2 cases by $\mathrm{C} 1,14$ cases by $\mathrm{C} 2$ and 6 cases by $\mathrm{C} 3{ }^{[10]}$.

- In Anakwe et al. (2010) ${ }^{[11]}$ reported that $\mathrm{b} 4$ cases by $\mathrm{C} 1$, 8 cases by $\mathrm{C} 2$ and 9 cases by $\mathrm{C} 3{ }^{[11]}$.

- In Khan SM et al. (2017) study AO A2 type most commonly encountered ${ }^{[11]}$.

\section{c) Radiological parameter}

Table 6: Radiological parameter

\begin{tabular}{|c|c|c|c|}
\hline Mean & In our study & $\begin{array}{c}\text { Marco Rizzo } \\
\text { et al. }\end{array}$ & $\begin{array}{c}\text { Tamara D } \\
\text { et al. }\end{array}$ \\
\hline Articular step up(mm) & 0.29 & 0.2 & - \\
\hline Radial height (mm) & 10.63 & 11 & 11 \\
\hline Radial inclination (degree) & 21.68 & 23 & 21 \\
\hline Volar tilt(degree) & 7.13 & 11 & 5 \\
\hline
\end{tabular}

\section{d) Complications}

In our study $6(15.7 \%)$ patients has complications. 1 has wound dehiscence, 2 has wrist stiffness, 1 has finger stiffness and 2 has occasional pain. There were no tendon or neurovascular injuries. Complications was treated by pain managements, antibiotics, physiotherapy.

Observations in previous studies

- In Arora Rohit et al., (2007) ${ }^{[7]}$ study he reported a complication rate of $57 \%$ [7].

- In Ayhn Kilic et al., (2009) ${ }^{[10]}$ study he reported a complication rate of $11.1 \%{ }^{[10]}$.

- In R.E. Anakwe et al. (2010) ${ }^{[11]}$ study he reported a complication rate of $4.8 \%{ }^{[11]}$

\section{e) Clinical Outcome}

Based on Demerit point system of Gartland and Werley.

In our study, 25(65.8\%) patients has excellent result, 10 (26.3\%) patients has good result, $3(7.9 \%)$ patients has fair results

Patients, who got excellent results, had normal regular activities or no pain and with normal range of motion, Radial length, volar tilt and articular step-off were within acceptable limits. They underwent early rehabilitation.

Patients with good results had minimal residual deformities, pain and slight limitation.

Patients with fair results, had residual deformity, pain and limitation also had pain in the distal radio-ulnar joint and minimal complications. Few of their movements were less than that required for normal function.

Observations in previous studies

- In Arora R et al. (2007) ${ }^{[7]}$ study found that $31 \%$ patients had excellent results, $54 \%$ had good results, $23 \%$ patients had fair results and $6 \%$ had poor results ${ }^{[7]}$.

- In Ayhan Kilic et al. (2009) ${ }^{[10]}$ study found that $44.4 \%$ patients had excellent results, $44.4 \%$ patients had good results, $11.2 \%$ patients had fair results ${ }^{[10]}$.

- In Khan SM et al. (2016) ${ }^{[21]}$ study found that $14(70 \%)$ patients had excellent result, 4 (20\%) had good results, 2 $(10 \%)$ had fair results this parameter similar to our study [11].

\section{f) Limitation}

Each research work is subjected to certain limitations and our study is not an exceptions

- Our study could have been better if we have compared with other modality of distal end radius fracture treatments.

- Ours study has maximum fallow up is 6 month we should follow the patients for longer.

- The sample size of our study was 38 patients, in future we might be able to conduct the study in larger patients.

- In our study we only included closed fractures.

- In our study we evaluated functional outcome by using only one scoring system, it would have been better if we used more than one scoring system.

\section{Conclusion}

From our study, we concluded that

1) Open reduction and plating is a better surgical modality in order to get good early functional results and early rehabilitation.

2) Perfect anatomic reduction is much needed for better functional and radiological outcomes after surgical fixation of distal radius fractures.

3) Open reduction and internal fixation of the distal radius is preferable in those patients who are young, athletes and who require to get back early to pre fracture state.

4) Volar locking plate is useful implant in stabilizing in osteoporotic and comminuted distal end radius fractures.

5) Volar locking plate is better option of dorsally displaced distal end radius fractures.

6) Complication rate are low in volar locking plate.

\section{Recommendations}

1) We recommend that use of locked volar plates in daily practice as reliable method of treatment of extra-articular and intr-articular fractures.

2) Use of volar locking plate is satisfactory method of treatments in both dorsal and volar tilt distal end radius fractures.

\section{References}

1. Aggarwal AK, Nagi ON. Open reduction and internal fixation of volar Barton's fractures: a prospective study. Journal of Orthopaedic Surgery. 2004; 12(2):230-4.

2. Barton T, Chambers C, Lane E, Bannister G. Do Kirschner wires maintain reduction of displaced Colles' fractures?. Injury. 2005; 36(12):1431-4.

3. Musgrave DS, Idler RS. Volar fixation of dorsally 
displaced distal radius fractures using the 2.4-mm locking compression plates. Journal of Hand Surgery. 2005; 30(4):743-9.

4. Cognet JM, Geanah A, Marsal C, Kadoch V, Gouzou S, Simon P. Plate fixation with locking screw for distal fractures of the radius. Revue de chirurgie orthopedique et reparatrice de l'appareil moteur. 2006; 92(7):663-72. 104.

5. Rozental TD, Blazar PE. Functional outcome and complications after volar plating for dorsally displaced, unstable fractures of the distal radius. Journal of Hand Surgery. 2006; 31(3):359-65.

6. Strohm PC, Müller CA, Helwig P, Mohr B, Südkamp NP. Is the locking, 3.5mm Palmar T-Plate the implant of choice for displaced distal radius fractures. Orthop Unfall. 2007; 145(3):331-7.

7. Arora R, Lutz M, Hennerbichler A, Krappinger D, Espen $\mathrm{D}$, Gabl M. Complications following internal fixation of unstable distal radius fracture with a palmar lockingplate. Journal of orthopaedic trauma. 2007; 21(5):316-22.

8. Levin SM, Nelson CO, Botts JD, Teplitz GA, Kwon Y, Serra-Hsu F. Biomechanical evaluation of volar locking plates for distal radius fractures. Hand. 2008; 3(1):55-60.

9. Rizzo M, Katt BA, Carothers JT. Comparison of locked volar plating versus pinning and external fixation in the treatment of unstable intraarticular distal radius fractures. Hand. 2008; 3(2):111-7.

10. Kilic A, Kabukçuoğlu Y, Ozkaya U, Gül M, Sökücü S, Ozdoğan U. Volar locking plate fixation of unstable distal radius fractures. Acta orthopaedica et traumatologica turcica. 2009; 43(4):303-8.

11. Anakwe RE, Khan LA, Cook RE, McEachan JE. Locked volar plating for complex distal radius fractures: Patient reported outcomes and satisfaction. Journal of orthopaedic surgery and research. 2010; 5(1):51.

12. Xavier CR, Dal Molin DC, Dos Santos RM, Dos Santos RD, Neto JC. Surgical treatment of distal radius fractures with a volar locked plate: correlation of clinical and radiographic results. Revista Brasileira de Ortopedia (English Edition). 2011; 46(5):505-13.

13. Minegishi H, Dohi O, An S, Sato H. Treatment of unstable distal radius fractures with the volar locking plate. Upsala journal of medical sciences. 2011; 116(4):280-4.

14. Dillingham C, Horodyski M, Struk AM, Wright T. Rate of improvement following volar plate open reduction and internal fixation of distal radius fractures. Advances in orthopedics, 2011.

15. Phadnis J, Trompeter A, Gallagher $\mathrm{K}$, Bradshaw L, Elliott DS, Newman KJ. Mid-term functional outcome after the internal fixation of distal radius fractures. Journal of orthopaedic surgery and research. 2012; $7(1): 4$.

16. Karantana A, Downing ND, Forward DP, Hatton M, Taylor AM, Scammell BE et al. Surgical treatment of distal radial fractures with a volar locking plate versus conventional percutaneous methods: a randomized controlled trial. JBJS. 2013; 95(19):1737-44.

17. Gyaneshwar T, Kumar GA, Parvez A, Gajraj S, Shantanu J, Kumar A. Anatomical and functional evaluation of distal end radius fractures managed by volar plating: a prospective study. Journal of Evolution of Medical and Dental Sciences. 2013; 2(7):802-12.

18. Shukla R, Jain RK, Sharma NK, Kumar R. External fixation versus volar locking plate for displaced intra- articular distal radius fractures: a prospective randomized comparative study of the functional outcomes. Journal of orthopaedics and traumatology. 2014; 15(4):265-70.

19. Franceschi F, Franceschetti E, Paciotti M, Cancilleri F, Maffulli N, Denaro V. Volar locking plates versus Kwire/pin fixation for the treatment of distal radial fractures: a systematic review and quantitative synthesis. British medical bulletin. 2015; 115(1):91-110.

20. MacFarlane RJ, Miller D, Wilson L, Meyer C, Kerin C, Ford DJ et al. Functional outcome and complications at 2.5 years following volar locking plate fixation of distal radius fractures. Journal of hand and microsurgery. 2015; 7(1):18-24.

21. Khan SM, Saxena NK, Singhania SK, Gudhe M, Nikose $\mathrm{S}$, Arora $\mathrm{M}$ et al. Volar plating in distal end radius fractures and its clinical and radiological outcome as compared to other methods of treatment. Journal of Orthopaedics and Allied Sciences. 2016; 4(1):40. 